\title{
Primary Perivascular Epithelioid Cell Tumor (Pecoma) of Bladder: Case Report and Review of
} Literature

\author{
Shiv Pankaj Khanna ${ }^{1}$, MD, Rigvardhan ${ }^{2}$, MD, Prabal Deb ${ }^{3}$, MD \\ ${ }^{1}$ Associate Professor, Department of Pathology, Command Hospital, Lucknow \\ ${ }^{2}$ Associate professor, Department of Pathology, Saraswati Medical College, Unnao \\ ${ }^{3}$ Professor, Department of Pathology, Army Hospital (Referral \& Research), Delhi
}

\begin{abstract}
Perivascular epithelioid cell neoplasms (PEComas) represent a rare family of neoplasms. Their dichotomous phenotypic features, including both myogenic and melanocytic features can make a definitive diagnosis difficult. So far 15 cases of PEComa urinary bladder have been reported. We describe a case of PEComa bladder for its rarity along with review of literature.
\end{abstract}

Keywords: PEComa, urinary bladder.

\section{Introduction}

Primary perivascular epithelioid cell neoplasms are a rare and unusual group of mesenchymal neoplasms with unpredictable malignant potential. ${ }^{[1]}$ Perivasculassr epithelioid cell neoplasms are defined by the World Health Organization as "mesenchymal tumors composed of histologically and immunohistochemically distinctive perivascular epithelioid cells". ${ }^{[2]}$ The term "PEComa" was originally coined by Zamboni et al and is the current nomenclature for tumors composed of PECs other than angiomyolipoma (AML), clear cell sugar tumor of lung (CCST) and lymphangioleiomyomatosis (LAM), which are related lesions with distinct clinical features. ${ }^{[3]}$ After World Health Organization's (WHO) endorsed PEComa as a bonafide entity, an increasing number of reports have documented PEComas arising in varied locations, including bladder, kidney and prostate. ${ }^{[4]}$ Herein, we report a case of primary PEComa of the urinary bladder.

\section{Case Presentation}

A 43 year old male presented with pain abdomen and epigastric discomfort of one month duration. There was no history of hematuria, dysuria, increased frequency, urgency, fever or weight loss. General physical and systemic examination was normal. Routine haematological and biochemical investigations were within normal limits. Ultrasound revealed a 2.6 x $2.8 \times 3.2 \mathrm{~cm}$ mixed hypo and hyperechoic lobulated lesion in the right lateral Table 1: Immunohistochemistry

\begin{tabular}{|l|c|c|c|c|c|c|c|c|c|}
\hline \multicolumn{1}{|c|}{$\begin{array}{c}\text { DIFFERENTIAL } \\
\text { DIAGNOSIS }\end{array}$} & $\begin{array}{c}\text { VIME } \\
\text { NTIN }\end{array}$ & CK \& EMA & SMA & DESMIN & MSA & HMB & $\begin{array}{c}\text { MELAN } \\
\text { A5 }\end{array}$ & $\begin{array}{c}\text { S-100 } \\
\text { SYNATOPH } \\
\text { YSIN }\end{array}$ \\
\hline $\begin{array}{l}\text { EPITHELIOID } \\
\text { LEIOMYOSARCOMA }\end{array}$ & + & - & + & - & + & - & - \\
\hline $\begin{array}{l}\text { UROTHELIAL } \\
\text { CARCINOMA }\end{array}$ & - & + & - & - & - & - \\
\hline
\end{tabular}

wall of the bladder. Bilateral kidneys were unremarkable. CT scan confirmed a $34.2 \times 28.4 \times 24 \mathrm{~mm}$ avidly enhancing soft tissue density mass in relation to right wall of urinary bladder, with a predominant exophytic component with lobulated contours and smooth margins. Minimal perivesical fat stranding was seen. Transurethral resection of tumour was performed. Per operatively 3 x $4 \mathrm{~cm}$ smooth tumour originating from right lateral aspect of urinary bladder was visualised with overlying mucosa intact and normal.

On gross examination the specimen consisted of four grey brown tissue bits, largest measuring $1 \times 0.5 \times 0.5 \mathrm{~cm}$. On microscopy, polygonal neoplastic cells were seen infiltrating the muscle fibres (fig 1A). These cells were oriented along the vascular channels in sheets with well defined cell outlines, moderate to abundant clear/vacuolated cytoplasm and vesicular nucleus with conspicuous nucleoli was seen (fig 1B). These tumor cells were also seen in fascicles with spindle cell morphology showing oval nuclei with vesicular chromatin and conspicuous nucleoli (fig 1C). No pleomorphism, necrosis or mitosis noted.

The main differential diagnosis in our case was epithelioid leimyosarcoma, urothelial carcinoma, neuroendocrine carcinoma and melanoma. Immunohistochemistry was performed which revealed positivity for Vimentin, Smooth muscle actin and HMB45 (fig 2). The immunohistochemistry profile of various differential diagnosis are summarized in table 1. 
International Journal of Innovative Research in Medical Science (IJIRMS)

Volume 03 Issue 08 August 2018, ISSN: 2455-8737, Imp. Factor - 4.102

Available online at - $\underline{w} w$ w. ijirms.in

NEUROENDOCRINE

VARIABLE

CARCINOMA

MELANOMA

PECOMA

Fig 1: A: polygonal neoplastic cells were seen infiltrating the muscle fibres (100x). B: Tumour cells were seen in sheets (100x) and fascicles $(C ; 200 x)$.

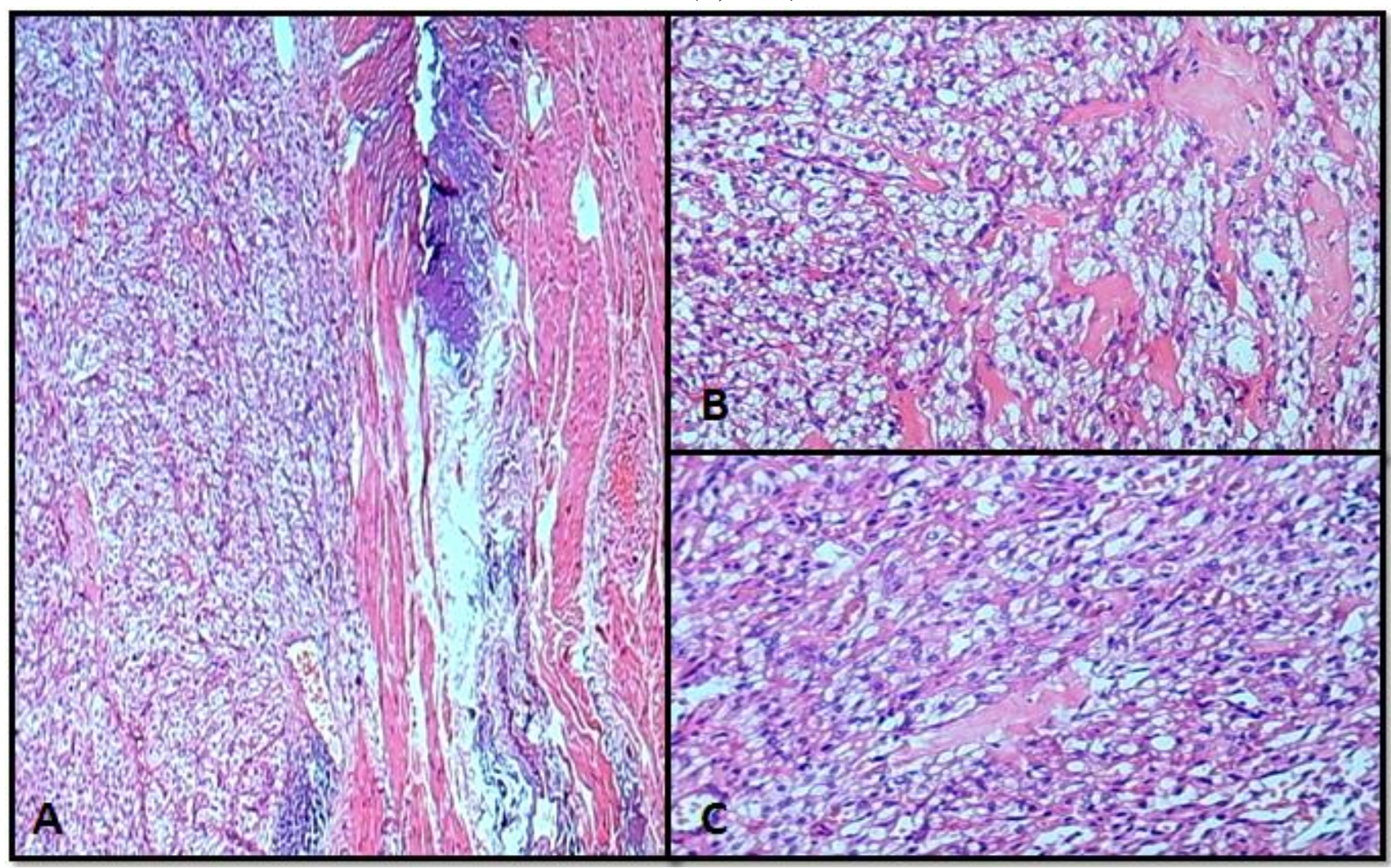

Fig 2: The tumour cells were immunopositive for HMB-45 (A), Smooth muscle actin (B) and Vimentin (C).

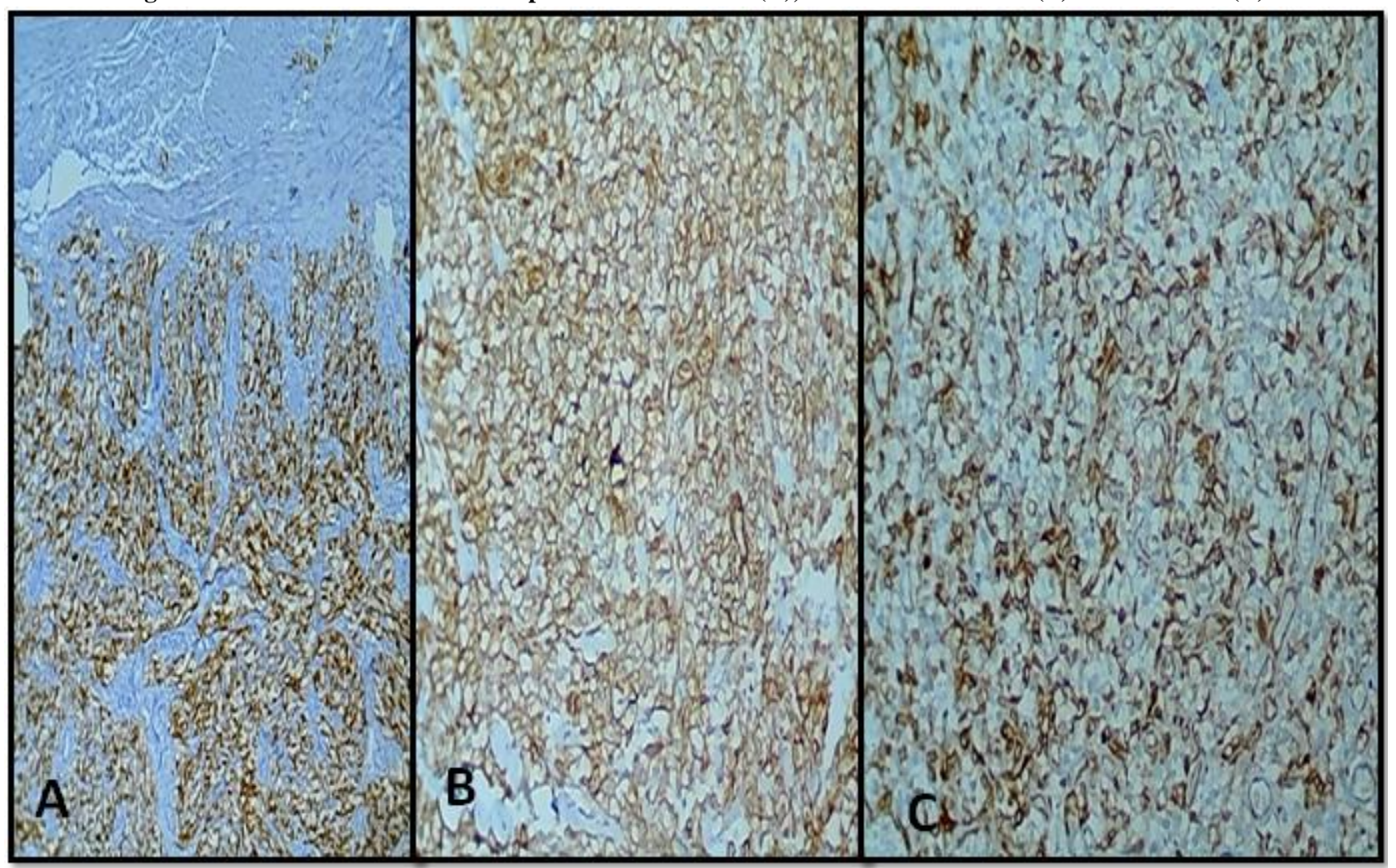


International Journal of Innovative Research in Medical Science (IJIRMS)

Volume 03 Issue 08 August 2018, ISSN: 2455-8737, Imp. Factor - 4.102

Available online at - $w w w$.ijirms.in

\section{Discussion}

Perivascular epithelioid cell tumors (PEComa) are a very uncommon mesenchymal cancer with uncertain malignant potential and only 15 cases have been reported so far in urinary bladder. ${ }^{[5]}$

These tumors have in common the presence of epithelioid to spindle cells with eosinophilic to clear cytoplasm. These tumours demonstrate positive immunostaining for markers of both myoid (smooth muscle actin, desmin) and melanocytic (HMB45, MelanA, tyrosinase) differentiation with few exceptions. ${ }^{[1]}$

While distinct clinicopathological entities included within the PEComa group are AML, LAM and CCST, other PEC-derived tumors have been documented at an increasing number of anatomical sites, including pancreas, intestine, common bile duct, bladder, prostate, breast, female urogenital system, heart, base of skull, and soft tissue. ${ }^{[6]}$

PEComas demonstrate uncertain malignant potential and unpredictable clinical behavior. While the majority of reported "PEComas" have behaved in a benign fashion but they do exhibit malignant behavior. ${ }^{[7]}$

When Folpe et al combined results of 24 of their own cases of PEComa of soft tissue and gynecological origin with data from 45 previously reported cases of PEComa, they found that recurrence and metastasis were associated with tumor size $>5 \mathrm{~cm}$, infiltrative growth pattern, high nuclear grade, necrosis and a mitotic index of $>1$ per 50 high power fields. ${ }^{[8]}$ However, other authors feel that accurate criteria which reliably predict the behavior of PEComas remain lacking. ${ }^{[1]}$

The PEComas with malignant potential are usually associated with overexpression of transcription factor E3 (TFE 3). The TFE 3 rearrangement associated PEComas have exhibited distinct pathologic characteristic in that they have predominantly epithelioid nested or alveolar pathology and underexpression of muscle markers by immunohistochemistry. Recently Xp11 translocation has been described with malignant PEComa. ${ }^{[7,9]}$

Optimal treatment for PEComas is not known at this time. Primary excision is usually curative, as most tumors are benign. Complete excision seems to be curative and is necessary to avoid progression. However, locally advanced or metastatic disease portends a poor prognosis and strategies incorporating chemotherapy, radiation and immunotherapy have been reported. $^{[1,2]}$

To conclude, despite increasing awareness of this entity, accurately predicting the biological behavior of PEComas remains difficult and contemporary reports are limited by short clinical follow-up. ${ }^{[1]}$

\section{Conflict of Interests}

All authors have none to declare.

\section{References}

[1] Parfitt JR, Bella AJ, Wehrli BM, Izawa JI. Primary PEComa of the bladder treated with primary excision and adjuvant interferon- alpha immunotherapy: a case report. BMC Urology 2006; 6:20-25.

[2] Lijuan Yin, Hong Bu, Min Chen, Jianqun Yu, Hua Zhuang, Jie Chen, and Hongying Zhang. Perivascular epithelioid cell neoplasm of the urinary bladder in an adolescent: a case report and review of the literature. Diagn Pathol. 2012; 7: 183. doi: 10.1186/1746-1596-7183.

[3] Zamboni G, Pea M, Martignoni G, Zancanaro C, Faccioli G, Gilioli E, Pederzoli P, Bonetti F. Clear cell "sugar" tumor of the pancreas. A novel member of the family of lesions characterized by the presence of perivascular epithelioid cells. Am J Surg Pathol 1996, 20:722-730.

[4] Folpe AL. Neoplasms with perivascular epithelioid cell differentiation (PEComas). In World Health Organization Classification of Tumors: Pathology and Genetics of Tumors of Soft Tissue and Bone. Edited by Fletcher CDM, Unni KK, Mertens F. Lyon: IARC Press; 2002:221-222.

[5] Sarti A, Rubilotta E, Balzarro M, Cerruto MA, Brunelli M, Artibani W. Bladder perivascular epithelioid cell tumor (PEComa): a case report and literature review. Urologia. 2014. doi: 10.5301/urologia.5000045.

[6] Pan CC, Yu IT, Yang AH, Chiang H: Clear cell myomelanocytic tumor of the urinary bladder. Am J Surg Pathol 2003, 27:689-692.

[7] Williamson SR, Bunde PJ, Montironi R, Lopez-Beltran A, Zhang S, Wang M, Maclennan GT, Cheng L. Malignant perivascular epithelioid cell neoplasm (PEComa) of the urinary bladder with TFE3 gene rearrangement: clinicopathologic, immunohistochemical, and molecular features. Am J Surg Pathol. 2013; 37(10):1619-26. doi: 10.1097/PAS.0b013e318293729d.

[8] Folpe AL, Mentzel T, Lehr HA, Fisher C, Balzer BL, Weiss SW. Perivascular epithelioid cell neoplasms of soft tissue and gynecologic origin: a clinicopathologic study of 26 cases and review of the literature.Am J Surg Pathol 2005, 29:1558-1575.

[9] Russell CM, Buethe DD, Dickinson S, Sexton WJ. Perivascular epithelioid cell tumor (PEComa) of the urinary bladder associated with Xp11 translocation. Ann Clin Lab Sci. 2014 Winter; 44(1):91-8.

\section{*Corresponding Author -}

Dr (Lt Col) Rigvardhan

Associate Professor,

Department of Pathology, Saraswati Medical College Unnao209859

Email: vardhanrig [at] yahoo.com 